\title{
A desconstrução do conceito de "qualidade da informação" *
}

\section{Rosa Maria Quadros Nehmy Isis Paim}

\section{Resumo \\ Tomando como principal referencial as categorias analíticas de Gaston de Bachelard - estádios de um conceito e obstáculo epistemológico -, a leitura da noção "qualidade da informação", tal como é abordada na literatura, revela que se trata de uma noção vaga, imprecisa, situando-se muito próxima ao entendimento do senso comum. As definições geralmente baseiam- se na adscrição de atributos passíveis de mensuração. A tendência dominante é a de se imprimir um julgamento de valor positivo à informação, relegando-se a um plano secundário seu lado negativo. Com essas características, a noção pode ser enquadrada na categoria bachelardiana do realismo ingênuo, que funciona como obstáculo epistemológico ao conhecimento. $A$ análise de outras noções correlatas conduz à constatação de que prevalecem condições semelhantes às assinaladas para a qualidade. A desconstrução das noções relativas à avaliação da informação constitui-se, pois, em um passo necessário para propiciar o redirecionamento da construção conceitual, de modo a sintonizar-se com as exigências do novo momento tecnológico e social.}

\section{Palavras-chave}

Qualidade da informação; Epistemologia e ciência da informação; Obstáculo epistemológico em ciência da informação: Avaliação da informação.

\section{INTRODUÇÃO}

Neste artigo, pretendemos focalizar a discussão nas formas de abordagem da qualidade da informação na literatura, no esforço de se desvelarem limitações e desafios para a construção teórica do conceito, partindo-se do pressuposto de a ciência da informação constituir-se em uma disciplina da área das humanidades. Apesar de dever ser levada em conta a recomendação de Wersig (1993) que julga ser o primeiro passo para o desenvolvimento do campo da ciência da informação o de se reformularem conceitos relevantes já existentes para o propósito da disciplina-, acreditamos que uma etapa anterior deva ser considerada, qual seja a de se efetuar a crítica dos conceitos ou noções em uso. A desconstrução de discursos e de conceitos surge como uma etapa necessária para propiciar o repensar da pesquisa e da atuação cotidiana.

As discussões vindas da filosofia da ciência e das ciências sociais, aliadas aos desafios das novas formas de comunicação através das redes de computadores, exigem que se enfrentem novas questões na abordagem da informação. Chega-se a perceber o reflexo dessas questões na literatura da ciência da informação, ao se identificar uma espécie de perplexidade entre seus praticantes, como se a segurança de seu objeto de trabalho e de pesquisa, localizado na concretude das instituições bibliotecárias e dos documentos, tivesse sido rompida por novos elementos e novas demandas que o desenvolvimento tecnológico e o movimento social têm trazido. O discurso da moder-

* Este artigo faz parte de uma série de três, fruto da pesquisa desenvolvida pelas autoras, cujos resultados preliminares foram apresentados na dissertação de mestrado: Nehmy, R.M.Q. Leitura epistemológico-social da "qualidade da informação”, Belo Horizonte: PPGCI/ UFMG, 1996. nidade tem questionado a certeza do conhecimento e em conseqüência a possibilidade de se utilizarem parâmetros permanentes para o julgamento de qualquer proposição, seja ela de origem científica ou prática. O tema da qualidade remete diretamente ao cerne do problema, na medida em que a própria palavra traz em si uma conotação de julgamento de valor.

O debate sobre a qualidade tem tido ressonância na ciência da informação, e uma prova de sua importância estána realização de um seminário em Copenhagem-Dinamarca, em 1989, promovido pelo Nordic Concil for Scientific Information and Research Libraries (Nordinfo), dedicado ao tema. Constituise, sem dúvida, no esforço mais importante de teorização sobre a qualidade da informação. Worwell (1990), editora da publicação resultante do seminário, testemunha a relevância do tema para os praticantes da ciência da informação. A autora revela ter percebido uma considerável demanda de sistematização dos vários aspectos e dimensões que recobrem esse complexo tema. Uma das autoras dessa publicação, Ingwersen (1992), propõe a abordagem da relevância, uso e valor da informação como foco de uma das cinco grandes áreas do campo de estudos.

O primeiro contato com a literatura revelou que vários outros termos eram utilizados para a abordagem da avaliação da informação de uma forma similar à da qualidade, e entre eles o mais freqüente era o uso de 'valor' como equivalente à qualidade. Ora, a palavra valor tem várias conotações, que vão da filosófica à econômica. Embora não houvesse a delimitação clara na literatura sobre que enfoque estava sendo privilegiado, ficava nítida a predominância da ênfase, que poderíamos caracterizar como 'extra-econômica', nas abordagens do tema. Como bem lembra 
Repo (1989), quando praticantes da área tomam o termo valor estão-Ihe atribuindo significação mais próxima ao 'valor de uso', deixando o 'valor de troca' para os economistas. A conotação de valor aproximada à idéia de valor de uso foi adotada por razões práticas como equivalente à qualidade, embora, ao longo deste artigo, diferenças entre os dois termos tenham sido postas em evidência.

A abordagem da avaliação da informação por meio do termo qualidade vem marcadamente da área da gerência de serviços. Foi possível identificar algumas outras noções, além da qualidade, que pareciam predominantes na literatura sobre avaliação da informação, tais como 'eficácia' no discurso gerencial, 'impacto' nas propostas de informação para o desenvolvimento, 'relevância' no discurso bibliotecário e 'autoridade cognitiva' relativamente à informação científica. Apesar de estarem situadas em contextos diversos de apreensão da avaliação da informação no discurso disciplinar, a passagem por essas concepções mostrou-se importante para o desvendamento do modo predominante de olhar o fenômeno na ciência da informação.

Para a leitura dos textos, tomou-se como principal referencial conceitual a epistemologia de Bachelard (1978.a; 1978.b), principalmente por meio de suas concepções sobre os 'estádios de um conceito científico' e de 'obstáculo epistemológico'. Foram chamados ainda outros autores que sugerissem críticas e perspectivas alternativas de abordagem para compor o cenário de confronto com as noções usuais de avaliação da informação. Do cenário fazem parte tanto autores da ciência da informação em sentido estrito (artigos publicados em fontes reconhecidas como pertencentes à área), quanto de outros campos de conhecimento que possam vir em respaldo às considerações feitas ao longo do texto.

A pesquisa bibliográfica, além da publicação resultante do Seminário NORDIN$\mathrm{FO}$, Information quality: definitions and dimensions, contemplou a busca de referências em textos e autores, nos índices LISA - Library and Information Science Abstracts e Library Literature, que abordassem explicitamente o tema da qualidade. Essa última estratégia mostrou-se de pronto infrutífera, pois os textos que traziam o termo no título referiam-se quase exclusivamente a artigos relativos a problemas específicos de administração de serviços, não se reportando a discussões teóricas, objeto de interesse deste trabalho. A revisão da literatura teve, em conseqüência, de percorrer outro caminho, através da garimpagem de artigos que abordassem o tema direta ou indiretamente.

\section{A VAGUEZA DA NOÇÃO}

Alguns trechos dos artigos da coletânea referente ao Seminário NORDINFO (1989) - cujo tema era a qualidade da informação - mostram como praticantes da área, ao se depararem com a exigência de elucidação teórica sobre o tema, revelam, de forma quase intuitiva, perplexidade ante a incerteza da noção e das dificuldades trazidas para sua aplicação a objetos específicos de estudo. Na introdução à coletânea, Wormell (1990, p.1), afirma que "as definições sobre a qualidade da informação têm sido feitas sob o ponto de vista de definições específicas e subjetivas, seguidas por definições ad hoc. Isso tem resultado em inúmeras interpretações pouco claras do conceito, imperfeitas e de alguma forma caóticas." * Em texto da mesma edição, Ginman (1990, p.18) ratifica essa percepção, quando diz: "Não há definição geralmente aceita sobre qualidade da informação. Para muitas pessoas o conceito tem aspectos vagos e subjetivos." Schwuchow (1990, p. 55) também revela ansiedade e perplexidade ao indagar: "O que é a qualidade no verdadeiro sentido da palavra? Esse é um dos termos mais ambíguos que já encontrei." Seu depoimento fica mais contundente em seguida ao explicitar ter ficado "muito frustrada", quando procurou o significado em dicionários e enciclopédias. Ou não encontrou o termo, ou não estava definido de forma bastante clara.

Wagner (1990, p.69), em artigo de apenas quatro páginas, propõe-se a realizar um balanço dos estudos teóricos sobre qualidade da informação e faz a seguinte declaração: "Há um problema de terminologia. O valor da informação, e não a qualidade, é o conceito preferido como se vê em valor de uso da infor-

* As traduções dos textos em inglês são de responsabilidade das autoras. mação, valor agregado da informação e valor de troca da informação. De outro lado, o uso do termo 'qualidade da informação' é escasso na literatura". O mesmo autor conclui pela necessidade de aprofundamentos teóricos sobre o tema. Em suas palavras: "Na era da informação, é uma profunda ironia a falta de um corpo sólido de trabalho teórico sobre qualidade e valor da informação. Essa área de conhecimento carece de síntese ou mesmo de um compêndio que reúna os estudos teóricos."

As percepções dos autores, cujos trechos foram anteriormente sublinhados, pontuam a vagueza, a imprecisão conceitual e a escassez de construção teórica, características que vão se inscrever no que Bachelard (1978.a) denomina de 'obstáculo epistemológico' ao conhecimento. São noções que devem ser superadas, pois não permitem o desenvolvimento do conhecimento científico. É de se interrogar se uma noção, capaz de confundir os próprios praticantes da área, não deva desde logo ser abandonada em favor de novo conceito. No entanto, a tendência dominante, pelo menos em certos setores da ciência da informação, notadamente a vertente gerencial, é a da busca de sua legitimação como conceito, o que já pôde ser entrevisto nas impressões iniciais dos autores considerados.

\section{A ANÁLISE DE MARCHAND DAS DEFINIÇÕES DE QUALIDADE DA INFORMAÇÃO}

Marchand (1990), em artigo onde se propõe fazer um inventário das propostas teóricas de tratamento da qualidade da informação, identifica cinco tendências de definição do conceito na literatura: abordagem 'transcendente', abordagens baseadas 'no usuário', 'no produto', e 'na produção', e abordagem 'da qualidade como um dos aspectos do valor'. Entretanto, de fato, as categorias que 0 autor propõe não são mutuamente exclusivas, e essas cinco tendências podem ser agrupadas, do ponto de vista teórico, nas duas grandes linhas de pensamento dominantes na ciência da informação: a vertente que enfatiza o produto (informação enquanto coisa) e a centrada no usuário (abordagem subjetiva). As três outras formas sugeridas pelo autor - 'transcendente', 'baseada na produção' e 'qualidade enquanto atri- 
buto do valor' - são dimensões que podem ser incluídas nessas duas linhas. No entanto, a distinção feita por Marchand (1990) das cinco formas de definição da qualidade da informação é útil e servirá como referência para a discussão que se segue porque permite destacar pressupostos teórico-ideológicos por trás de cada dimensão.

A abordagem 'transcendente” é aquela que tende a perceber o valor da informação como absoluta e universalmente reconhecido (Marchand, 1990). Para o autor, a qualidade nesse sentido é sinônimo de excelência, é extratemporal e permanente, com características que se mantêm apesar da mudança de gostos e estilos. Mas ele próprio questiona essa categoria. Utilizando, como exemplo, a obra de Platão A República, argumenta que ela só tem validade para os ocidentais. Conclui que a universalidade da excelência e da durabilidade é relativa ao usuário, o que estaria a demonstrar a ambigüidade da definição.

Cooney (1991, p. 179), ao se referir ao atributo permanente da informação, utiliza a expressão "qualidade intrínseca". ${ }^{* \star}$ Diz o autor: "Pode-se considerar a informação do ponto de vista do valor intrínseco que ela possui. Um poema ou uma fórmula matemática, por exemplo, podem possuir qualidades tais como elegância, introspeção, expressão precisa..., que lhes conferem um valor indiscutível, pelo menos em um sentido metafísico. Entretanto, o valor econômico de tal informação, ou seja, o que o mercado se dispõe a pagar por ela pode aproximar-se de zero." Na mesma direção, ao discutirem a possibilidade de a informação ser considerada como um recurso econômico ou uma mercadoria, Eaton e Bawden (1991) citam vários argumentos encontrados na literatura que reforçam a posição de negação de um valor real à informação. Afirmam que a informação não possui valor intrínseco, pois o valor está na dependência do contexto e de sua utilização por usuários particulares em ocasiões particula-

\footnotetext{
* Autores como, por exemplo, Repo (1989), preferem denominar essa abordagem como "filosófica".

** As outras abordagens da informação que o autor considera particularmente dignas de menção são o efeito do custo, oferta e procura e utilidade (Cooney, 1991).
}

res, sendo impossível, assim, determinar-se a priorio valor que ela possui para seu usuário. A ênfase no usuário e a conseqüente negação de qualquer valor "objetivo" à informação é definitivamente assumida por Connel (1981, p. 79). O autor é taxativo ao declarar: "A informação não tem valor intrínseco, seu valor é inteiramente subjetivo. A informação não varia em valor por causa de suas características externas... seu valor está na mente do usuário." Casanova (1990, p.42) contrapõe-se à proposição de que a informação não teria uma qualidade/valor intrínseco, mas o tipo de valor ao qual alude aproxima-se mais da idéia de um valor atribuído ao produto, e não de um valor filosófico ou metafísico. Após afirmar que informação não é opinião, acrescenta: "Informação tem características intrínsecas, como responsabilidade, confiabilidade, objetividade, abrangência, precisão, capacidade de ser transmitida, suporte material".

Conforme pode ser visto por meio dos exemplos, ao se considerar a existência de uma qualidade/valor permanente da informação, estabelece-se certa confusão na compreensão do que seja esse tipo de valor. Às vezes é tomado pelo lado metafísico, impregnado de virtudes como verdade ou beleza, por exemplo, e outras vezes é considerado como "atributos do produto". Ora, a negação de um valor filosófico ou metafísico à informação representa uma espécie de perigo para a abordagem da informação, porque, partindo desse pressuposto, nada teria valor, tudo seria contingente. A advertência que faz Bourdieu (1997, p.38), um dos mais importantes cientistas sociais contemporâneos, em contexto diferente, mas válido para o objeto em foco, é extremamente pertinente. Sua declaração merece ser transcrita na íntegra: "Ora, é importante saber que todas as produções culturais que considero - e não sou o único, espero que certo número de pessoas considera como as produções mais elevadas da humanidade, a matemática, a poesia, a literatura, a filosofia, todas essas coisas foram produzidas contra o equivalente do índice de audiência, contra a lógica do comercial. Ver introduzir-se essa mentalidade-índice até entre os editores de vanguarda, até nas instituições científicas, que se propõem a fazer marketing, é muito preocupante porque isso pode colocar em questão as condições mesmas da produção de obras que podem parecer esotéricas, porque não vão ao encontro de seu público, mas, com o tempo, são capazes de criar seu público."*

Marchand (1990) separa as dimensões 'transcendente' e 'baseada no produto' como diferentes modos de pensar a qualidade da informação. A definição baseada no produto é compreendida por ele como a abordagem que tende a ver a qualidade da informação em termos precisos e identificáveis, sendo seus atributos passíveis de serem mensurados e quantificados. Considerada assim, a noção de qualidade está em sintonia com a linha teórica proposta por Buckland (1991) para o entendimento da 'informação enquanto coisa'. Nesse contexto, o termo informação é utilizado enquanto atributo de objetos, tais como dados, textos e documentos, que são mencionados como informação porque são considerados como informativos. Procura-se atribuir valor a "coisas pelas quais alguém se torna informado" porque outras dimensões da informação são intangíveis, não podendo ser apreendidas empiricamente (Buckland, 1991; Vakkari, 1992). De um modo ou de outro, considerando-se a qualidade como transcendente ou intrínseca, notase uma tendência a se negar um valor permanente à informação em favor de uma postura extremamente relativista de privilégio ao usuário. A dimensão propriamente filosófica, apesar de mencionada na literatura, é no fundo desprezada, com o argumento de sua impermeabilidade à operacionalização**.

A respeito do enfoque que privilegia o usuário, Marchand (1990) pontua que, para essa corrente (a terceira dimensão por ele assinalada, que denomina 'baseada no usuário'), entram em jogo no julgamento da excelência as particularidades individuais. Assim, os tipos e fontes de informação que mais satisfizessem o usuário seriam as considera-

\footnotetext{
* Bourdieu (1997), nessa citação, alude ao problema de os jornalistas se prenderem a índices de audiência, o que funciona como um tipo de censura para o que deve ou não deve ser mostrado na televisão. O significado de audiência está próximo ao significado de uso do ponto de vista da ciência da informação.

** O abandono da filosofia - deve ser destacado - é um dos postulados fundamentais do positivismo na ciência (Comte, 1978).
} 
das de melhor qualidade. Wagner (1990, p.70), referindo-se às tendências dominantes sobre a qualidade da informação, vai afirmar que "uma teoria consistente que emerge de vários estudos é a de que o valor da informação depende do usuário e do contexto em que ela é vista. Dessa forma, o usuário, quer individual quer coletivo, faz o julgamento da qualidade ou valor da informação."

Para esse autor, o usuário conforma a base das abordagens comportamentalistas sobre o valor da informação, principalmente em algumas teorias da tomada de decisão e conclui ser essa uma tendência importante que parece tomar corpo no campo da ciência da informação. Marchand (1990) demonstra ter restrição a essa forma de abordagem porque carregaria um ponto de vista altamente subjetivo, invocando como justificativa de sua crítica o argumento da pouca possibilidade de operacionalização que ela permite.

A quarta visão, que Marchand (1990) identifica como 'baseada na produção', tende a ver quase sempre a qualidade como adequação a padrões estabelecidos de necessidade de informação do consumidor. Desvios em relação aos padrões significariam redução da qualidade da informação. Apesar da distinção atribuída pelo autor a esse tipo de abordagem, observa-se que, enquanto tendência teórica, não aparece com muita força na literatura da ciência da informação. Trata-se mais de uma preocupação de caráter operacional para administração de serviços particulares de informação, * e não de um projeto de base conceitual. Na aparência, a proposta geral de abordagem da qualidade da informação pelo lado da produção apresenta um traço marcante de contaminação com a ideologia da qualidade total, tomada como um novo modo de organização do processo de trabalho das empresas, em substituição ao taylorismo e ao fordismo (Pinto, 1994). ${ }^{* *}$ Pinto

\footnotetext{
* Encontra-se uma literatura abundante sobre a qualidade da informação encarada desse ponto de vista. Um exemplo é a edição especial sobre o tema na revista Ciência da Informação, IBICT, v.22, n.2, 1993.

** Tal dedução é possível, porque, em geral, os autores com preocupações teóricas não fazem referência a textos ou à bibliografia específica dos programas de qualidade total, não explicitando, portanto, influência dessa fonte.
}

(1994) identifica esse programa como uma cultura que extrapola o ambiente das empresas, invadindo a sociedade mais ampla. Na literatura relativa ao tema da qualidade da informação, Casanova (1990) identifica a qualidade total "quase como um objetivo universal nos negócios, na cultura, no lazer e até na vida privada". Nesse sentido, o propósito da abordagem da qualidade da informação baseada na produção pode ser vista como aquela tendência que, de um modo geral, visa a expor e aplicar princípios do programa de qualidade total a serviços de informação.

A última vertente apontada por Marchand (1990) toma a qualidade enquanto um dos atributos do valor. Apesar de o autor não exemplificar essa abordagem, a proposta de Taylor (1985), ao considerar a qualidade como um dos aspectos da definição de 'valor agregado', pode ser enquadrada nessa categoria. * A limitação que Marchand (1990) aponta para abordagens que entendem a qualidade como um aspecto do valor reside na dificuldade de sua aplicação, porque considera tratar-se de dois conceitos qualidade e valor - que, embora correlacionados, teriam natureza distinta. Apesar de pontuar a distinção, o autor não demonstra as diferenças entre eles. Para o interesse da presente discussão é importante destacar que, considerando essa vertente, o valor é pensado como a categoria mais abrangente e a qualidade como um de seus atributos, o que reforça a percepção da ambigüidade do uso dos dois termos na literatura.

\footnotetext{
* A proposta de Taylor encaixa-se na categoria "baseada na produção" segundo a classificação de Marchand (1990), mas o autor sublinha a dependência em relação ao usuário para o estabelecimento do valor. Taylor (1985) considera a qualidade como uma das dimensões do 'valor agregado' da informação, o qual significa um processo em que a informação se torna mais valiosa quando é organizada, sintetizada e julgada. As outras dimensões, paralelas à qualidade, são 'acesso', 'facilidade de uso', 'adaptabilidade', 'economia de custo e de tempo'. O autor atribui à qualidade um significado mais próximo da idéia de excelência em relação às outras dimensões do valor agregado, conforme pode ser percebido pelos aspectos incorporados indicadores de qualidade. Estão incluídas na categoria qualidade as características de precisão, abrangência, atualidade, confiabilidade e validade de dados e informações de um sistema.
}

TENTATIVAS DE TEORIZAÇÃO DA “QUALIDADE” DA INFORMAÇÃO

Como conclusão de sua análise, Marchand (1990) afirma que as cinco abordagens da qualidade da informação por ele consideradas partilham de um problema comum, qual seja, o de oferecer somente uma visão parcial e por vezes vaga dos elementos básicos da qualidade da informação. Procurando superar as limitações por ele mesmo apontadas, constrói uma tipologia da qualidade da informação. O modelo proposto pelo autor e as classificações de Repo (1989) e Olaisen (1990) foram selecionados como exemplares de tentativas de teorização da qualidade ou valor da informação. Como se poderá notar, essas classificações operam sem discriminar o tipo de abordagem em que se apóiam. As duas grandes linhas teóricas - "baseada no produto" e "no usuário" - aparecem de modo combinado. A ênfase maior das categorizações está na identificação de atributos de qualidade, cada autor elegendo um determinado espectro deles, os quais, por diferentes vias de classificação, são agrupados sob os termos qualidade ou valor.

Marchand (1990, p.11-12) propõe desagregar o conceito de qualidade da informação em oito dimensões inter-relacionadas: valor real, características suplementares, confiança, significado no tempo, relevância, validade, estética e valor percebido. Ao listá-las, mais do que defini-las, tece comentários sobre cada uma delas, os quais diluem o poder de sua utilização como categorias descritivas. Em relação à dimensão 'valor real', faz alusão à variabilidade da percepção do valor do produto (informação ou serviço), dependente de estilos individuais de tomada de decisão. Sobre as 'características suplementares à utilidade básica de um produto ou serviço de informação', faz um alerta sobre os diferentes pesos que as características da informação podem ter em contextos diversos de tomadas de decisão. Com referência à 'confiança', lembra a existência de atitudes contraditórias de confiança em relação a fontes. Sobre a dimensão 'significado no tempo', faz alusão à variabilidade da atualidade da informação em diferentes contextos de tomadas de decisão. Na definição de 'relevância', invoca as diferenças na 
percepção da relevância da informação entre projetistas de sistemas e agentes da tomada de decisão. Em relação à dimensão 'validade', comenta sobre a variação da percepção da validade da informação, dependente de quem a fornece e de como é apresentada. Sobre a 'estética', menciona a subjetividade do aspecto estético da informação. E, finalmente, arrola a dimensão 'valor percebido', quando aponta a irracionalidade da atribuição de reputação pelo usuário a sistemas de informação. Ao final, conclui que a lista proposta sugere "como é difícil descrever e medir a informação." Essa dificuldade, acrescenta, encontra-se também expressa na existência das cinco formas de abordagem da qualidade da informação na literatura. Pode-se verificar, pois, que os comentários feitos pelo autor em torno dos atributos da qualidade diluem a idéia de excelência nos vários fatores assinalados e colocam em cena aquele que utiliza a informação, o usuário, como contraponto necessário a uma pretensa objetividade da noção.

Repo (1989), em artigo no qual se dispõe a demonstrar a contribuição de idéias e instrumentos de economistas para a análise prática do valor da informação, chega à conclusão de que, embora haja interesse teórico sobre o tema, os estudos realizados são de um modo geral pouco produtivos em termos práticos para se medir a informação. Além disso, acentua que em geral os estudos vindos da ciência da informação não fazem distinção entre valor de uso e de troca. Sugere, como um modo de se iniciar a organização da pesquisa, o uso da dupla abordagem do valor: valor de troca (caráter econômico) e valor de uso (caráter cognitivo). Diz Repo (1989, p. 81) que "o aspecto filosófico (emocional, espiritual, social...)" conforma a base da análise do valor da informação. Entretanto, o próprio autor deixa em suspenso o valor filosófico ao afirmar que seu papel não será explorado no artigo, porque ele depende, na prática, dos indivíduos, e sua importância tende a refletir a avaliação de usuários individuais da informação. Os 'valores práticos' dividem-se, para ele, em 'valor de troca' de produtos da informação (serviço, canal ou sistema), o que corresponderia à abordagem "baseada no produto" de acordo com a classificação de Marchand(1990), e 'valor de uso' que leva em consideração o usuário, o uso e os efeitos do uso da informação, subdividido em "valor esperado" e "valor percebido", categorias que se enquadram na abordagem "baseada no usuário" proposta por aquele mesmo autor. A caracterização proposta, segundo Repo (1989), permitiria a apreensão do valor da informação sob a forma de medida, embora ressalte que, na maioria das vezes, o valor de uso só possa ser apreendido por medidas qualitativas. O modelo proposto pelo autor a partir da noção de valor separa em categorias o valor de uso e de troca, reportando à teoria da economia política e delega a abordagem do aspecto do valor de uso para os cientistas da informação. A idéia de valor de uso tal como o autor sustenta está muito próxima à visão de qualidade na literatura da ciência da informação, ao se remeter à percepção do usuário, através das categorias valor esperado e valor percebido - cujos conteúdos significativos não são elaborados pelo autor, mas que denotam um aporte inteiramente subjetivo de avaliação.

Olaisen (1990) procura privilegiar o caráter qualitativo da avaliação da informação no contexto da tecnologia eletrônica. Partindo de um quadro de referência de corte fenomenológico, da teoria da administração de serviços e de um estudo empírico, propõe, ao final, um modelo onde aspectos usuais da qualidade são agrupados em quatro categorias: qualidade cognitiva, qualidade do desenho da informação, fatores referentes ao produto da informação e fatores relativos à qualidade da transmissão. A 'qualidade cognitiva' é dependente de como a fonte é valorizada pelo usuário. Nessa categoria, incluem-se os seguintes aspectos: 'credibilidade', 'relevância', 'confiança', 'validade' e 'significado no tempo'. A 'qualidade do desenho da informação' incorpora fatores referentes à 'forma', 'flexibilidade' e 'seletividade'. Os fatores referentes 'ao produto da informação' são 'valor real' e 'abrangência' e, finalmente, os fatores relativos à 'qualidade da transmissão' são definidos pelo critério da 'acessibilidade'. O conjunto dos fatores e a relação entre eles configuram o que o autor denomina de 'processo de qualidade da informação'. Pode-se inferir de sua proposta que a idéia de excelência, de modo implícito, perpassa as várias dimensões. Mas, pondera o autor, somente quando um usuário usa uma fonte é que se decide se as expectativas foram atendidas ou superadas (satisfação do consumidor), ou não atendidas (insatisfação do consumidor). Ao se remeter ao usuário, a idéia de excelência perde a força, acabando por se igualar, como se vê, à noção de satisfação-insatisfação. A ênfase dada no estudo à autoridade cognitiva do ponto de vista da fenomenologia para avaliação da fonte da informação prometia um aporte diferenciado para a questão da qualidade. No entanto, o autor termina por propor uma lista de fatores destinados à mensuração semeIhante às demais abordagens.

Após a exposição dos modos de abordagens a partir de Marchand (1990) e dos três modelos, ficam evidenciados problemas teórico-metodológicos a permear a questão da qualidade da informação. Quando há referência à qualidade, muitas vezes ela é tomada como a categoria mais ampliada e por outras é vista como um entre outros aspectos da avaliação da informação. Os termos qualidade e valor são apropriados geralmente como equivalentes, e não há elaboração teórica suficiente de modo a diferenciá-los da noção do senso comum. Mesmo quando se fazem referências ao valor de uso da informação, noção com maior densidade teórica, não se segue o rigor exigido pela teoria da economia política, ao trazê-la para o estudo da qualidade da informação. Tais constatações induzem à retomada do ponto de partida, quando se aludiu à vagueza, imprecisão e ambigüidade da noção. Parece, pois, justificada a perplexidade revelada de início por alguns dos autores ao serem provocados a pensar sobre ela. O paradoxo reside no fato de que, apesar da vagueza a revestir o conceito e do reconhecimento tácito sobre a imprecisão das noções com que trabalham, os autores geralmente demonstram uma preocupação comum: a de traduzir a qualidade da informação em atributos imediatos. As definições dadas à noção concentram-se no levantamento de aspectos, dimensões, atributos ou características do fenômeno. O desejo da medida está expresso tanto nas intenções dos autores de reconhecer na qualidade atributos imediatos, quanto na revelação de insatisfação com definições correntes, exatamente porque os aspectos atribuídos à noção não permitem a operacionalização através de 
índices ou medidas (Marchand, 1990; Buckland, 1991). Em suma, antes de se alcançar o conceito, pretende-se medilo. Dessa forma, a noção da qualidade como é tratada na literatura da ciência da informação, apesar dos esforços de construção teórica, pode-se caracterizar como uma noção que se situa na categoria bachelardiana do realismo ingênuo (Lecourt, 1977)*, estádio da história de um conceito que ainda não rompeu com o mundo sensível. Como afirma Bachelard (1978.a; 1978.b) ${ }^{\star \star}$, um conceito com essas características bloqueia o conhecimento, não o resume.

\section{OUTRAS NOÇÕES DE AVALIAÇÃO DA INFORMAÇÃO}

Como pôde ser visto, ocorre, na maioria das vezes, a sobreposição de uso dos dois termos qualidade e valor para referir-se a algo como a excelência da informação. No exame da literatura, encontram-se ainda outras noções paralelas à da qualidade/valor que assumem conotação semelhante à idéia de exce-

\footnotetext{
* Para Bachelard, há uma gradação progressiva entre as várias filosofias: do realismo ingênuo, passando ao empirismo claro e positivista ao racionalismo clássico da mecânica racional, ao racionalismo completo da teoria da relatividade até o racionalismo discursivo, última etapa de seu programa epistemológico. Cada noção, segundo ele, como, por exemplo, as noções de massas e de energia, tem diferente peso de cada uma daquelas filosofias, podendo ser traçado um perfil epistemológico de cada uma das noções. Segundo sua reflexão, a ruptura com o realismo ingênuo e o positivismo está no corte da noção científica com a 'coisa'. Tomando como parâmetro a física contemporânea, vai afirmar que os fenômenos ambíguos da ciência moderna jamais referem-se a 'nossas coisas', são construções racionalistas onde se fundem ação e coisa, objeto e movimento (Lecourt, 1977). Os objetos são representados por metáforas, sua organização é que representa o papel de realidade. Nesse caso, o hipotético é o 'nosso' fenômeno, porque, diz ele, "nosso contato com o real só vale como um dado confuso, provisório, convencional e esse contato fenomenológico exige inventário e classificação. A reflexão é que dará novo sentido ao fenômeno inicial... A priori, não podemos ter qualquer confiança na instrução que o dado imediato pretende nos fornecer. Nem é juiz, nem testemunha: é um acusado, réu que cedo ou tarde se convence da mentira. O conhecimento científico é sempre a reforma de uma ilusão". (Lecourt, 1977, p. 15).
}

** Bachelard (1978.a; 1978.b) opõe-se, radicalmente, à afirmação que impõe uma leitura necessariamente sensível do conhecimento científico que pretende reduzir a experimentação a uma série de leituras de índices. lência. Após referir-se à ambigüidade da definição de qualidade e à dificuldade de se submeterem seus indicadores usuais à medida, Schwuchow (1990) propõe a adoção da noção de 'eficácia' para avaliação de produtos e serviços de informação. O autor não chega a definir o termo diretamente, mas expõe a proposição de que a eficácia depende da adequação a demandas do usuário.

O que, afirma, equivale a dizer que a qualidade (ou o desempenho) de sistemas de informação não pode ser determinada 'objetivamente' no sentido de que o resultado de uma avaliação possa ser independente da pessoa que a tenha feito: "É, ao contrário, dependente da situação do usuário e da natureza de seu problema, o que vai determinar que aspectos da eficácia influenciam o julgamento do sistema como um todo." (Schwuchow, 1990, p. 59). O autor propõe um modelo de procedimentos de objetivação da base de julgamento, submetendo uma lista de critérios de avaliação a diferentes avaliadores - como, por exemplo, usuários e operadores de sistema -, procurando atingir, mediante artifícios metodológicos, a construção de um consenso de medida do grupo de avaliadores. Mas conclui ser difícil obter uma única medida para os serviços de informação e acrescenta ser tal modelo muito complexo, demorado e dispendioso. Por tais razões, vai dizer, tende-se normalmente a reduzir a avaliação da informação a apenas alguns aspectos. Esse comentário de ordem prática para justificar a redução do escopo da avaliação representa, no mínimo, uma extremada simplificação da questão teórico-metodológica a ser enfrentada.

Em outra perspectiva discursiva, 'Saracevic (1992) afirma que, durante décadas, os principais critérios para a abordagem da avaliação da informação foram 'relevância' e 'utilidade'. Mas comenta que também se ouve alusão - na maioria das vezes de forma oral - a diferentes critérios, alguns relacionados à qualidade, seletividade, precisão, poder de síntese ou impacto da informação. O autor traz como problematização para o campo de estudos a necessidade de revisão dos antigos critérios de avaliação da informação. Propõe que se restaure o conceito de 'eficácia' - o qual, da forma como expõe, engloba a idéia de qualidade - no sentido de se atender às novas pressões que a sociedade da informação e o correlato desenvolvimento da tecnologia vêm fazendo à ciência da informação. A explosão de publicações, por exemplo, diz ele, é um fato, da mesma forma que é um fato demonstrado por vários estudos empíricos que apenas uma pequena proporção delas é altamente utilizada, considerada de alta qualidade ou citada. $\mathrm{Pa}$ rece, diz o autor, estar ocorrendo um processo de seleção natural darwiniano na literatura. Sugere como problemas a serem enfrentados os seguintes: a clarificação dos novos conceitos de qualidade (eficácia), a avaliação de sua operacionalização e sua relação com os antigos critérios de relevância e utilidade. Afinal, conclui, a conformação de sistemas e serviços de informação a serem futuramente elaborados estará determinada pelas respostas gerais a tais questões.

Nos discursos sobre a informação científica, a abordagem da avaliação da informação implica a utilização de noções similares à idéia de qualidade como excelência. Embora o termo qualidade não seja utilizado freqüentemente, a avaliação da informação científica aparece como um dos temas de interesse da área. Editores e bibliotecários diretamente envolvidos com decisões sobre a publicação de artigos, no primeiro caso ou com a gerência de serviços de informação de uma biblioteca, no segundo, concentram-se em critérios externos para a avaliação tais como a revisão de especialistas, análises de citações, autoridade cognitiva (prestígio do autor e das instituições de origem do texto) e outros (Neill, 1989).

A revisão de especialistas por assunto (peer review) é vista como o critério mais forte para a avaliação da qualidade do artigo científico (Abelson, 1990; Crawford e Stucki, 1990; Neill, 1989). Apesar de alegadas limitações da revisão por especialistas como critério de qualidade da produção científica, como lembra Neill (1989, p. 4-5), propostas de avaliação feitas do ponto de vista de analistas da informação, no sentido de agir como um filtro de qualidade, envolveriam tantas variáveis que as tornariam impraticáveis em situações concretas. Além disso, continua o autor, estudos bibliométricos têm demonstrado que seus 
resultados estão positivamente correlacionados com as avaliações dos especialistas. Ora, os padrões de excelência hoje seguidos pelos especialistas dos vários ramos de conhecimento estão desmistificados pela visão da ciência na modernidade. Conforme a filosofia da ciência, esta é uma atividade regulada pela intersubjetividade dos cientistas de uma comunidade especializada de praticantes: “...uma comunidade científica ao adquirir um paradigma adquire igualmente um critério para a escolha de problemas que, enquanto o paradigma for aceito, poderemos considerar como dotados de uma solução possível. Em uma larga medida, esses são os únicos problemas que a comunidade admitirá como científicos ou encorajará seus membros a resolver." Kuhn (1994, p. 60). Sendo assim, a tentativa de se criarem critérios "objetivos" capazes de fornecer algum parâmetro de avaliação da informação científica fica em suspenso.

Na circunstância de ser necessário aterse a critérios externos de avaliação, a tematização sobre a qualidade da informação científica está permeada pelos mesmos problemas que perpassam os outros aportes da avaliação da informação considerados até aqui, persistindo o uso de categorias estritamente descritivas. Por exemplo, a análise de citações como critério de qualidade da produção científica acaba por se referir aos aspectos de 'utilidade' ou 'relevância'* julgados pelo usuário da literatura de uma determinada comunidade científica. Nesse caso, a medida da qualidade (ou de seus termos equivalentes) será dada pelo número de citações recebidas pelo artigo científico. Outros critérios utilizados são aqueles relativos à 'autoridade cognitiva' da fonte, os quais se reportam ao prestígio da instituição, do autor ou a prêmios recebidos. Sendo assim, não se vislumbra, na tematização sobre a qualidade ou noções correlatas referente à informação científi-

\footnotetext{
* Vale a pena destacar que Harter e Hooten (1992), por exemplo, utilizam as palavras qualidade, utilidade ou relevância como termos equivalentes, ao relatarem resultados de pesquisa sobre a relação entre citações e financiamento em publicações da ciência da informação. Essa pontuação vem em reforço das considerações feitas à frente sobre a confusão existente no uso de termos referentes à avaliação da informação.
}

ca, propostas com densidade significativa para o enriquecimento de seu conteúdo simbólico.

Nos discursos originários da documentação e recuperação da informação, principalmente naqueles relativos a bibliotecas, não se costuma operar de modo direto com o termo de qualidade. A noção principal em torno da avaliação da informação é a de 'relevância', cuja tradição remonta aos anos 50 (Saracevic, 1970). Apesar de existir uma volumosa literatura sobre relevância, o conhecimento formal sobre o tema é inadequado, e pesquisas empíricas costumam ainda ser desenvolvidas, adotando-se um significado intuitivo para o termo (Saracevic, 1970; Eisemberg, Schamber, 1988; Park, 1993). A maior preocupação da tradição na biblioteconomia é a pesquisa sobre a denominada 'relevância objetiva' que trabalha a partir de hipóteses de adequação dos tópicos de indexação e classificação de documentos às questões de pesquisa bibliográfica, onde a questão de pesquisa é definida pela representação de uma necessidade de informação. Em tal perspectiva a relevância é a medida da adequação entre uma fonte e um destinatário (Saracevic, 1970, 1975; Harter, 1992). Como contraponto, propostas mais recentes de entendimento da relevância do ponto de vista do usuário tendem a atribuir ao termo o significado de 'pertinência' e 'utilidade' sentidas pelo usuário da informação. A ênfase passa a ser delegada à 'relevância psicológica', tendência reforçada pelo projeto teórico de inspiração cognitiva (Harter, 1992). Em síntese, a noção de qualidade - e a correlata idéia de excelência - fica bastante atenuada quando se pensa a avaliação a partir da relevância. Ou trata-se de avaliar a adequação de tópicos aos objetivos de pesquisas bibliográficas - onde o problema é o de se verificar se determinada escoIha de termos feita pelo cientista da informação é apropriada a um saber especializado - , ou instaura-se o domínio do usuário pela ênfase na relevância psicológica. Deve-se notar ainda que, em algumas tipologias sobre a qualidade, a relevância é indicada como um de seus atributos, significando mais um ponto a caracterizar a imprecisão conceitual das noções.
Sob outra perspectiva de avaliação, a noção de 'impacto' é utilizada por programas de informação para o desenvolvimento. As medidas de impacto visam a descrever não só os tipos de informação, mas também o modo como são utilizadas nos diferentes níveis nacional, regional e local (Repo, 1989). Em um programa desse tipo, Menou (1993; 1995.a e 1995.b) sugere, nos marcos da proposta cognitiva, o emprego da noção de impacto considerada em seu texto como equivalente ao valor da informação. Em sua visão, o valor essencial da informação refere-se a um acréscimo em relação a um estágio prévio de conhecimento. No entanto, adverte, um estágio rico de conhecimento não garante seu uso de modo satisfatório. Será necessária uma nova passagem, a do conhecimento para a sabedoria (identificada por uma série de fatores filosóficos, sociológicos, culturais...), esta sim, capaz de instruir ações para a mudança (Menou, 1995.b). Mas, ressalta o autor, a sabedoria é obviamente um atributo do usuário ou receptor da informação. A proposta de Menou distingue-se da maioria dos trabalhos sobre o tema, ao conferir maior densidade teórica ao debate. Também a indicação da direção do pensamento sobre o valor da informação parece justa, quando o autor destaca fatores socioculturais e filosóficos para a apreensão do valor. Entretanto, trata-se de proposições que precisam ainda ser mais elaboradas, conforme reconhece. Ao final, mantém-se em sua proposta o interesse primordial com a avaliação de tipo quantitativo, visando a encontrar índices de impacto da informação.

Em síntese, o cotejamento da noção de qualidade/valor, originada predominantemente da área de gerência de serviços com outras aproximadas como a noção de eficácia e aquelas vindas de outras linhas discursivas, como a do bibliotecário, do analista da informação científica ou da informação para o desenvolvimento, revela que não se modifica muito o modo de se acercar do fenômeno da avaliação da informação. Continuam válidas de uma forma geral as mesmas considerações feitas para a noção qualidade/valor de acordo com a epistemologia bachelardiana: persiste ainda o problema da condição empiricista dominante da(s) noção(ões). 


\section{O ESQUECIMENTO DO LADO NEGATIVO DA INFORMAÇÃO*}

Quando as definições de avaliação da informação (qualidade, impacto, relevância e outras) são problematizadas, na maioria das vezes - como o faz por exemplo, Marchand(1990) -, o tom mais constante é o de ênfase nas limitações para a abordagem quantitativa, e não nos desafios para a construção do conceito. Um desses desafios seria o de se considerar o lado negativo da informação. Conforme lembra Menou (1993, 1995.a), tem-se realçado o papel positivo da informação e sua contribuição para o esclarecimento das pessoas. Mas isso, complementa, seria mais devido à crença, por parte dos especialistas em informação, de que a informação e os sistemas de informação sejam relevantes para a tomada de decisão e a solução de problemas, não existindo, no entanto, evidências concretas (avaliações sistemáticas e quantitativas) sobre sua efetiva contribuição, soando mais como uma afirmação de caráter ideológico. Capurro (1992), concordando com Schader (1986), afirma que, no domínio da ciência da informação, a preocupação com a forma negativa, a desinformação e seus derivados (mentiras, propaganda, má interpretação, ilusão, erro, decepção...) é escassa na literatura.

A predominância da idéia de excelência nos discursos sobre a qualidade e noções correlatas impedem que se trate do lado negativo da informação. Embora não esteja explicitado pelos autores, as noções utilizadas pressupõem a existência de uma escala de gradação que contém em si um pólo negativo (maior ou menor qualidade, eficácia, relevância ou impacto). Mas o lado efetivamente negativo da informação - o

\footnotetext{
* Esta parte do artigo inspirou-se na indagação que faz Bachelard (1978.a) a respeito da noção de carga ou massa da psicologia. Em sua reflexão, indaga sobre o uso que alguns psicólogos falem da noção como se tratasse de conceito claro, mesmo sabendo da confusão que encerra. Quando um psicólogo cita 'carga de afetividade' está pressupondo uma massa mais ou menos intensa, não podendo referir-se a uma pequena massa reduzida de afetividade ou quando considera ser carga aquilo que sobrecarrega, está abandonando o conceito de massa efetiva. Emprega-se o conceito mais para significar o grande do que o pequeno. Bachelard exclama a respeito: "Estranha medida que só mede aquilo que cresce!". (Bachelard, 1978.a, p. 14).
}

erro, a desinformação... - não é abarcado por definições desse tipo, porque são outros fenômenos, cuja apreensão não passa por uma questão de grau, mas pela mudança no olhar. Ora, se a observação do esquecimento do lado negativo é pertinente para as noções de qualidade e correlatas, também o é para seu complemento, a informação. Em reforço à observação de Menou, podese observar, na literatura da ciência da informação, a existência de uma formulação geral de que a informação tenha em si uma conotação positiva (Vakkari, 1992; Buckland, 1991; Marchand, 1990; Olaisen, 1990). Informação é vista como igual a conhecimento, algo que vem em acréscimo ao estoque já apropriado pelo usuário ou consumidor da informação.

A presença de juízos de valor* (com valorização positiva) nas duas noções, informação e qualidade (ou noções correlatas assinaladas) chega a causar confusão entre os limites das significações a elas atribuídas. Uma proposição emblemática é feita por Harter (1992, p. 611612) ao sugerir a existência de uma relação íntima entre as noções de relevância e informação (como processo), de tal maneira a "não haver necessidade das duas idéias ou termos na ciência da informação." O emprego dos dois termos chegaria a ser prejudicial "para o desenvolvimento da teoria, podendo ser útil tomá-los como uma só e mesma idéia."

Em síntese, noções como qualidade, eficácia e outras assinaladas, ao assumirem uma carga valorativa tão evidente, não conseguem dar conta da complexidade dos fenômenos que se pretende estudar. Pode-se mesmo inferir que a proposição de que a informação pressupõe um valor positivo tenha contribuído para obscurecer sua dimensão negativa e com isso limitado as possibilidades de análise do papel da informação nos diversos contextos da sociedade e dos serviços de informação.

\footnotetext{
* Weber (1992) afirma que os juízos de valor não deveriam ser extraídos de maneira nenhuma da análise científica, devido ao fato de derivarem, em última instância, de determinados ideais e de por isso terem origens subjetivas. Embora Weber pretenda alcançar a objetividade científica, reconhece o papel dos valores na escolha do objeto de pesquisa. A alusão a Weber não exclui o reconhecimento da ideologia como elemento intrínseco das ciências sociais. (Demo, 1995, Popper, 1973).
}

\section{CONCLUSÃO}

Mesmo sem esgotar o conjunto dos discursos sobre a qualidade/valor e noções correlatas e sem a pretensão de se terem selecionado as noções mais importantes relativas à avaliação da informação, os exemplares analisados indicam a persistência de uma determinada forma de se tratar a questão. Mostram que, apesar das nuances de designações e significados atribuídas às noções, permanecem como núcleo de conteúdo significativo duas idéias principais, quais sejam, a de excelência - mais ou menos atenuada - e a de usuário. Resumindo, quando se tenta retirar o núcleo 'duro' das significações, resta a idéia de algo positivo que deve ser alcançado no trabalho com a informação. Por outra parte, a alusão constante ao usuário coloca-o como contraponto necessário à excelência, no julgamento de qualquer valor da informação. No entanto, no contexto dos discursos sobre a qualidade, nenhuma das duas noções - excelência ou usuário - está suficientemente trabalhada do ponto de vista teórico.

Por outro lado, as dúvidas expressas pelos praticantes da área em relação às significações atribuídas à qualidade da informação e às dificuldades levantadas sobre a aplicação das noções em situações concretas estão em sintonia com o tom da discussão da modernidade ou da pós-modernidade, cuja tônica é a relatividade do conhecimento (Giddens, 1991). De qualquer forma, a leitura realizada mostra ser infrutífero insistir no caminho já trilhado na construção de conceitos em torno da qualidade que tenha como base noções comprometidas com uma epistemologia empiricista. A elaboração conceitual deve romper com esses compromissos. As pistas teórico-metodológicas sugeridas por autores como Saracevic (1992) - quando acentua a necessidade de afinação do campo com os novos problemas tecnológicos e novas demandas sociais e Menou (1994) - ao mostrar a necessidade de se considerar, na avaliação do papel da informação, fatores relativos ao ambiente sociocultural e ético - podem redirecionar os estudos sobre o tema da qualidade de modo a permitir a compreensão do fenômeno e a criação de categorias analíticas que efetivamente informem a pesquisa e a prática. 


\section{REFERÊNCIAS BIBLIOGRÁFICAS}

1. ABELSON, P. Mechanisms for evaluating scientific information and the role of peer review. Journal of American Society for Information Science. n. 41, v.3, p. 216 222, 1990

2. BACHELARD, G. A filosofia do não. São Paulo: Abril Cultural, 1978.a. p.4-87.

3. BACHELARD, G. O novo espírito científico. São Paulo: Abril Cultural. 1978.b. p. 91-179.

4. BUCKLAND, M. K. Information as thing. Journal of American Society for Information Science. n. 42, v.5, p. 351-360, 1991

5. BOURDIEU, P. Sobre a televisão, Rio de Janeiro: Zahar, 1997.

6. CAPURRO, R. What is information science for? A philosophical reflection. In: VAKKARI, P., CRONIN, B. (Eds.) Conceptions of library and information science, London: Taylor Graham, 1992. p.82-96.

7. CASANOVA, M. B. Information: the major element for change. In: WORMELL, I, (Ed.) In formation quality: definitions and dimentions London: Taylor Graham. 1990. p. 42-53.

8. CIÊNCIA DA INFORMAÇÃO. Brasília: IBICT, v. 22, n. 2, 1993

9. COMTE, A. Discurso sobre o espírito positivo. In: GIANNOTI, J. (Ed.) Auguste Comte. São Paulo: Abril Cultural, 1978. p. 43-94.

10. CONNELL, J. J. The fallacy of information resource management. Infossystems v.28, n.5, p. 78-84, 1981

11. COONEY, J. P. Qual o real valor da informação? Rev. Esc. Biblioteconomia UFMG, v.20, n.2, p. 176-190, 1991.

12. CRAWFORD, S. \& STUCKI, L. Peer review and the changing research record. Journal of American Society for Information Science, v.41, n.3, p. 223-228, 1990.

13. DEMO, P. Débito social da ciência. In: Metodologia científica em ciências sociais. São Paulo: Atlas, 1995. p. 16-40.

14. EATON, J. J., BAWDEN, D. What kind of resource is information? International Journal of Information Management, n. 11, p. $156-165,1991$

15. EISEMBERG, M., SCHAMBER, L. Relevance: the search for a definition. Proceedings of 51'st Annual Meeting of American Society for Information Science, v.25, p. $164-168,1988$

16. GIDDENS, A. As consequências da modernidade. São Paulo: Editora da Universidade Estadual Paulista, 1991.
17. GINMAN, M. Quality information and information for quality. In: WORMELL, I. (Ed.) Information quality: definitions and dimentions, London: Taylor Graham, 1990. p.18-33.

18. GRIFFITHS, J. M. The value of information and related systems, products and services. Annual Review of Information Science and Technology, n.17, p.269-264, 1982.

19. HARTER, S. P. Psycological relevance and information science. Journal of American Society for Information Science, v. 43, n.9, p. 602-615, 1992

20. HARTER, S.P., HOOTEN, P. A. Information Science and scientists: JASIS, 1972-1990. Journal of American Society for Information Science, v. 43, n. 9, p. 583-593, 1992.

21. INGVERSON, P. Conceptions of information science. In: VAKKARI, P., CRONIN, B. (Eds.) Conceptions of library and information science. London, Los Angeles: Taylor Graham, 1992. p. 299-312.

22. KUHN, T. A estrutura das revoluções científicas. São Paulo, Perspectiva, 1994

23. LECOURT, D. (Ed.) Gaston Bachelard Epis temologia: trechos escolhidos. Rio de Janeiro: Zahar, 1977

24. MARCHAND, D. Managing information quality. In: WORMELL, I. (Ed.) Information quality: definitions and dimensions. London: Taylor Graham, 1990. p. 7-17.

25. MENOU, J.M. Measuring the impact of information on development. International Development Research Centre (IDRC), Otawa-Canada, 1993.

26. MENOU, J.M. The impact of information - I. Towards a research agenda for its definition and mesurement. Information Processing and Management, v.31, n.4, p. 455 477, 1995.

27. MENOU, J.M. The impact of information - II. Concepts of information and its value. Information Processing and Management, v.31, n.4, p.479-490, 1995

28. NEILL, S. D. The information analyst as a quality filter in the scientific communication process. Journal of Information Science, 15, p.3-12, 1989.

29. OLAISEN, J. Information quality factors and the cognitive authority of eletronic information. In: WORMELL, I. (Ed.) Information quality: definitions and dimensions. London: Taylor Graham, 1990. p. 84-91.

30. PARK, T. K. The nature of relevance in information science: an empirical study. Library Quarterly, v. 93, n.3, p. 318-351, 1993
31. PINTO, D. Qualidade: o novo paradigma da sociedade capitalista In: Cultura da qualidade versus qualidade de vida. Rio de Janeiro: PUC, 1995. p. 104-173. (Dissertação de Mestrado).

32. REPO, A.J. The value of information: approaches in economics, accounting and management science. Journal of American Society for Information Science, v. 40, $\mathrm{n}$. 2, p. 68-85, 1989

33. SARACEVIC, T. The concept of relevance in information science: a historical review. In: Introduction to information science, New York: Bowker, 1970. p.11-151.

34. SARACEVIC, T. Relevance: a review and framework for the thinking on the notion in information science. Journal of American Society for Information Science, v.6, n. 5 , p. 321-343, 1975

35. SARACEVIC, T. Information science: origin evolution and relations. In: VAKKARI, $P$. CRONIN, B. (Eds.) Conceptions of library and information science. London: Taylor Graham, 1992. p.5-27.

36. SCHRADER, A. The domain of information science: problems in conceptualization and in consensus building. Information Services \& Use, p.169-205, 1986.

37. SCHWUCHOW, W. Problems in evaluating the quality of information services. In: WORMELL, I. (Ed.) Information quality: definitions and dimensions. London: Taylor Graham, 1990. p.69-72.

38. TAYLOR, R. S. Information values in decision contexts. Information Management Review, v. 1, n.1, p.47-55, Summer, 1985.

39. VAKKARI, P. Library and information science: its context and scope. In: Advances in Librarianship, v. 18. Academic Press Incorporation, 1994. p.1-55.

40. WAGNER, G. The value and the quality of information: the need for a theoretical syntesis; In: WORMELL, I. (Ed.) Information quality: definitions and dimentions, London: Taylor Graham, 1990. p. 69-72.

41. WEBER, M. Max Weber: metodologia das ciências sociais - parte 1. São Paulo: Cortez, 1992

42. WERSIG, G. Information science: the study of postmodern knowledge, Information Processing \& Management, v. 29, n. 2, p. 229-239, 1993.

43. WORMELL, I. Introduction. In: WORMELL, I. (Ed.) Information quality: definitions and dimentions, London: Taylor Graham, 1990. p.1-6. 


\section{The de-construction of "information quality" concept}

\section{Abstract}

By taking as main theoretical references $G$. Bachlard's analytical categories - stages of a concept and epistemological obstacle -, the analysis of the information quality notion, such as it is approached in the literature, reveals that it is a vague and inaccurate notion, very close to common sense judgement. Definitions are generally made Artigo aceito para publicação em 20-2-98. by means of addition of measurable atributes. The prevailing tendency leads to attributing a positive value to information, relegating its negative aspect to an inexpressive approach. Due to those characteristics, the notion can be framed in the Bachelardian category of "naive realism", which triggers 'epistemological obstacle" to knowledge. The analysis of correlate notions leads to evidencing similar predominant conditions. The de-construction of notions related to information evaluation is then a necessary step to allow conceptual construction to take a new direction, in a way to be tuned with demands posed by the present technologial and social moment.

\section{Keywords}

Information quality; Epistemology and information science; Epistemological obstacle; Information evaluation.

\section{Rosa Maria Quadros Nehmy}

Socióloga, mestre em ciência da informação e doutoranda do Programa de Pós-Graduação em Ciência da Informação da Escola de Biblioteconomia da UFMG.

\section{Isis Paim}

Ph.D. em educação superior pela universidade de Vanderbilt, professora e coordenadora do Programa de Pós-Graduação em Ciência da Informação da Escola de Biblioteconomia da UFMG.

E-mail: isispaim@eb.ufmg.br 